\title{
CRISPR-Cas9 Multiplex Editing of the $\alpha$-Amylase/Trypsin Inhibitor Genes to Reduce Allergen Proteins in Durum Wheat
}

\author{
Francesco Camerlengo ${ }^{1}$, Arianna Frittelli ${ }^{1}$, Caroline Sparks ${ }^{2}$, Angela Doherty ${ }^{2}$, \\ Damiano Martignago ${ }^{2 \dagger}$, Colette Larré ${ }^{3}$, Roberta Lupi ${ }^{3}$, Francesco Sestili ${ }^{1 *}$ and \\ Stefania Masci ${ }^{\text {1* }}$
}

${ }^{1}$ Department of Agricultural and Forestry Sciences, University of Tuscia, Viterbo, Italy, ${ }^{2}$ Rothamsted Research, Harpenden, United Kingdom, ${ }^{3}$ INRAE UR1268 BIA, Impasse Thérèse Bertrand-Fontaine, Nantes, France

\section{OPEN ACCESS}

Edited by:

Jitendra Paul Khurana, University of Delhi, India

Reviewed by:

Ravinder K. Goyal, Agriculture and Agri-Food Canada

(AAFC), Canada

Mark Paul Running,

University of Louisville, United States

${ }^{*}$ Correspondence:

Francesco Sestill

francescosestili@unitus.it

Stefania Masci

masci@unitus.it

tPresent address:

Damiano Martignago,

Department of Biosciences, University

of Milano, Milan, Italy

Specialty section:

This article was submitted to

Crop Biology and Sustainability,

a section of the journal

Frontiers in Sustainable Food Systems

Received: 23 March 2020

Accepted: 11 June 2020

Published: 31 July 2020

Citation:

Camerlengo F, Frittelli A, Sparks C,

Doherty A, Martignago D, Larré C,

Lupi R, Sestili F and Masci S (2020) CRISPR-Cas9 Multiplex Editing of the $\alpha$-Amylase/Trypsin Inhibitor Genes to

Reduce Allergen Proteins in

Durum Wheat.

Front. Sustain. Food Syst. 4:104.

doi: 10.3389/fsufs.2020.00104
Wheat and its derived foods are widespread, representing one of the main food sources globally. During the last decades, the incidence of disorders related to wheat has become a global issue for the human population, probably linked to the spread of wheat-derived foods. It has been ascertained that structural and metabolic proteins, like $\alpha$-amylase/trypsin inhibitors (ATI), are involved in the onset of wheat allergies (bakers' asthma) and probably Non-Coeliac Wheat Sensitivity (NCWS). The ATI are a group of exogenous protease inhibitors, which are encoded by a multigene family dispersed over several chromosomes in durum and bread wheat. WTAI-CM3 and WTAI-CM16 subunits are considered among the main proteins involved in the onset of bakers' asthma and probably NCWS. A CRISPR-Cas9 multiplexing strategy was used to edit the ATI subunits WTAI-CM3 and WTAI-CM16 in the grain of the Italian durum wheat cultivar Svevo with the aim to produce wheat lines with reduced amount of potential allergens involved in adverse reactions. Using a marker gene-free approach, whereby plants are regenerated without selection agents, homozygous mutant plants without the presence of CRISPR vectors were obtained directly from $T_{0}$ generation. This study demonstrates the capability of CRISPR technology to knock out immunogenic proteins in a reduced time compared to conventional breeding programmes. The editing of the two target genes was confirmed either at molecular (sequencing and gene expression study) or biochemical (immunologic test) level. Noteworthy, as a pleiotropic effect, is the activation of the ATI 0.28 pseudogene in the edited lines.

Keywords: CRISPR-Cas9, durum wheat, multiplex editing, tRNA processing system, ATI, GM-free, NCWS, wheat allergies

\section{INTRODUCTION}

Wheat is the major staple food of the human diet and it is one of the most cultivated crops in the world. The reason for this prevalence is due to the unique properties of doughs formed from wheat flours, which allow them to be processed into a range of baked products (including bread, pizza, cakes, and biscuits), pasta and other processed foods (Shewry, 2009). The unique viscoelastic properties mainly depend on the composition and interaction of the gluten protein fraction, corresponding to glutenins, and gliadins (Shewry, 2009). 
However, in recent years there has been an increase in the incidence of wheat-related disorders in the world population. Among the wheat-related pathologies, the most well-known is Coeliac Disease (CD), caused by gluten proteins, but IgE and non-IgE mediated allergies, wheat-dependent exercise-induced anaphylaxis (WDEIA), Non-Coeliac Wheat Sensitivity (NCWS) and hypersensitivity to wheat represent a broad spectrum of disorders resulting from flour ingestion, inhalation, or contact (Cabanillas, 2019; Scherf, 2019), most of them caused by factors other than gluten proteins.

These adverse reactions to wheat are mainly due to the protein fraction of the wheat kernel. Gluten proteins are responsible for triggering CD and WDEIA (Tatham and Shewry, 2008), whereas structural and metabolic proteins, like $\alpha$-amylase/trypsin inhibitors (ATI), lipid transfer proteins (LTP), thioredoxins and puroindolines, are involved in the onset of other wheat allergies and probably NCWS (Weichel et al., 2006; Battais et al., 2008; Tatham and Shewry, 2008; Henggeler et al., 2017; Mansueto et al., 2019).

The ATI form a protein family and represent a substantial fraction of the albumins and globulins of wheat endosperm (2-4\% of total proteins) (Altenbach et al., 2011; Henggeler et al., 2017). They are inhibitors of heterologous $\alpha$-amylase and trypsin, thus they play an important protective role against insect, mite, and mammalian $\alpha$-amylase. Their synthesis takes place during seed development together with main storage proteins, and they are rapidly degraded upon germination and used by the plants as a nutritional reserve. ATI also prevent starch degradation during drought, adjusting the osmotic balance through the accumulation of starch within the cells, consequently they are overexpressed in drought-resistant genotypes (Gu et al., 2015). ATI subunits are low molecular weight proteins with molecular weights in the $12-16 \mathrm{KDa}$ range (about 150 amino acid residues). All ATI contain 10 cysteine residues and form 4 to 5 intrachain disulfide bonds with a common folding: 4-5 $\alpha$-helices and a short antiparallel $\beta$-sheet. Amino acid sequence identity between members of the family ranges from around 30 to 95\% (Carbonero and Garcia-Olmedo, 1999; Reig-Otero et al., 2018).

The ATI family includes different subunits that can be subdivided into monomeric (WMAI about $12 \mathrm{kDa}$ ), homodimeric (WDAI about $24 \mathrm{kDa}$ ), and heterotetrameric forms (WTAI about $60 \mathrm{kDa}$ ) based on their aggregation degree. This latter form consists of protein subunits soluble in chloroform/methanol mixtures (CM proteins) and each WTAI contains one subunit of CM1 or CM2, one subunit of CM16 or CM17 and two subunits of CM3 (Altenbach et al., 2011).

The genes encoding ATI are dispersed over several chromosomes. It is reported that WMAI are encoded by genes located on $6 \mathrm{~B}$ and $6 \mathrm{D}$ chromosomes, WDAI by genes on $3 \mathrm{~B}$ and $3 \mathrm{D}$ and WTAI are encoded by genes in chromosome group 7 and chromosome group 4 with the CM3 and CM16 subunits being encoded by genes located on $4 \mathrm{~B}$ and $4 \mathrm{D}$ chromosomes, respectively (Tatham and Shewry, 2008). The nucleotide sequences of all the ATI are highly conserved and there are no introns in their coding sequences (Wang et al., 2008).
In previous studies ATI sequences were identified in the A genome of wheat (both in bread and durum wheat), but these genes are silent or expressed at a low level (Zoccatelli et al., 2012; Capocchi et al., 2013). In addition, no activity against heterologous $\alpha$-amylase has been found in extracts from diploid wheat species with the A genome (García-Maroto et al., 1990, 1991; Dupont et al., 2011) and no inhibition of human $\alpha$-amylases has been detected in einkorn wheat (Reig-Otero et al., 2018). Lower bioactivity was observed in older wheat variants, including spelt (hexaploid wheat), emmer (tetraploid) and einkorn (diploid) (Zevallos et al., 2017).

ATI are now recognized to be the major triggering factors responsible for the onset of bakers' asthma and allergies to wheat (Kusaba-Nakayama et al., 2001; Pastorello et al., 2007; Tatham and Shewry, 2008; Junker et al., 2012; Zevallos et al., 2017). They are also putative factors in the establishment of Non-Coeliac Wheat Sensitivity (NCWS) in predisposed patients along with fermentable oligosaccharides and disaccharides, monosaccharides, and polyols (FODMAPs) (Carbonero and Garcia-Olmedo, 1999; Tatham and Shewry, 2008; Junker et al., 2012; Reig-Otero et al., 2018; Mansueto et al., 2019). ATI subunits are the most IgE-reactive proteins of the wheat kernel, particularly the subunits $0.19, \mathrm{CM} 2, \mathrm{CM} 3$, and CM16 which can trigger bakers' asthma, intestinal, and skin allergy to wheat and, in the glycosylated form, WTAI-CM16 exhibits the strongest binding to IgE in patients with bakers' asthma (Zapatero et al., 2003; Schuppan et al., 2015; Zevallos et al., 2017; Bellinghausen et al., 2019). Therefore, the ATI family could also be a prominent activator of the innate immune responses in Coeliac Disease (Schuppan et al., 2015; Zevallos et al., 2017; Bellinghausen et al., 2019), due to their resistance to human digestion, conferred by their three-dimensional compact structure characterized by four to five intramolecular disulfide bonds (Reig-Otero et al., 2018).

Through breeding, it may be possible to develop wheat varieties, which are safer both for consumers and for employees of the food industry. Moreover, modulation of the putative factors involved in wheat-related disorders could help to define their specific role in such pathologies. However, generation of new wheat genotypes is a lengthy process using conventional strategies, especially when gene families are to be targeted, as in the case of ATI.

Genome editing tools have evolved rapidly in recent years and, in particular, CRISPR-Cas9 technology could help breeding programmes reduce the time to produce new safer genotypes. Although to date the definition of GMOs is under discussion, we are confident that CRISPR-edited plants should not fall into this definition, thus facilitating their release onto the market.

Gene editing remains challenging in transformationrecalcitrant species, with relatively few experiments reported in the major crops, especially for durum and bread wheat (Kumar et al., 2019). However, the progress made in vector assembly, delivery systems and Cas proteins (Xie et al., 2015; Gil-Humanes et al., 2017; Bhowmik et al., 2018; Hamada et al., 2018; Qi et al., 2018; Liang et al., 2019; Zhang et al., 2019) could allow the editing of wheat varieties for multiple purposes, including the production of low immunogenic wheat varieties for patients with CD (Sánchez-León et al., 2018; Jouanin et al., 2019). 
In the present work, the multiplex editing of WTAI-CM3 and WTAI-CM16 subunits of the tetrameric form was obtained through CRISPR-Cas9 knockouts in the Italian durum wheat cultivar Svevo with a marker free approach, in order to obtain edited GM-free plants from the first generation.

The availability of genotypes with reduced amounts of ATI proteins might allow both the development of novel wheat cultivars with a lower triggering potential and enable a better understanding of the role of these components in wheatrelated pathologies.

\section{MATERIALS AND METHODS gRNAs Design and Plasmid Vector Assembly}

The guide RNA targets based on the coding sequence of CM3 and CM16 genes were designed using Deskgen Cloud (www. deskgen.com). On-target and Off-target activities predicted by the platform were taken into account, along with the location of the off-target hits across the genome, considering those without target specificity in coding sequences (Table 1). The secondary structure of each gRNA was also considered and predicted by RNAfold web server (www.rna.tbi.univie.ac.at/cgibin/RNAWebSuite/RNAfold.cgi).

The selected guides were synthesized in a tRNA/gRNA architecture to produce multiple gRNAs simultaneously, as reported by Xie et al. (2015). The polycistronic tRNA/gRNA (PTG) containing all the guides was constructed based on the Golden Gate (GG) assembly principle, starting from the pGTR plasmid (Addgene), and cloned into pRRes208.482 vector (provided by Rothamsted Research) under the control of the rice U3 small nucleolar RNA promoter (U3 snoRNA promoter).

The pRRes217.486 vector (Rothamsted Research) contains a wheat codon-optimized Cas9 under the control of a maize ubiquitin promoter (Zm Ubim3), two Nuclear Localization Signals (NLS) and nopaline synthase terminator (NosT) (Figure S1).

DNA parts used for PTG assembly were amplified using 50 $\mu l$ PCR reactions for each primer pair (Table S1). The PCR reactions were performed with $25 \mu$ l of 2 X GoTaq ${ }^{\circledR}$ G2 Hot Start Colorless Master Mix (Promega), $0.5 \mu \mathrm{M}$ of each primer, $20 \mathrm{ng}$ of template DNA (pGTR), and nuclease-free water to $50 \mu$ l volume, with the following conditions: $95^{\circ} \mathrm{C}$ for $2 \mathrm{~min}$, followed by 35 cycles at $95^{\circ} \mathrm{C}$ for $1 \mathrm{~min}, 61^{\circ} \mathrm{C}$ for $30 \mathrm{~s}, 72^{\circ} \mathrm{C}$ for $30 \mathrm{~s}$ and a final extension at $72^{\circ} \mathrm{C}$ for $5 \mathrm{~min}$.

The GG assembly reaction to ligate individual DNA parts and to build the PTG was performed in a final volume of $20 \mu \mathrm{l}$ containing $10 \mu \mathrm{l}$ of $2 \mathrm{x}$ T7 DNA ligase buffer, $2 \mu \mathrm{l}$ of Bovine Serum Albumin ( $1 \mathrm{mg} / \mathrm{ml}), 0.5 \mu \mathrm{l}$ of BsaI-HF (20 U/ $\mu \mathrm{l}, \mathrm{NEB}), 0.5 \mu \mathrm{l}$ of T7 DNA ligase $(3,000 \mathrm{U} / \mu \mathrm{l}, \mathrm{NEB}), 50 \mathrm{ng}$ of each DNA part and $75 \mathrm{ng}$ of pRRes208.482. The GG reaction was incubated at $37^{\circ} \mathrm{C}, 5 \mathrm{~min}$ and $20^{\circ} \mathrm{C}, 10 \mathrm{~min}$ for 50 cycles with a final step at $20^{\circ} \mathrm{C}, 1 \mathrm{~h}$. The BsaI sites added to the $5^{\prime}$ ends of BsaI_tRNA-F and BsaI_gRNA-R primers generate 4-bp overhangs that allow the ligation of the PTG into pRRes208.482 in a one-step, one tube reaction.

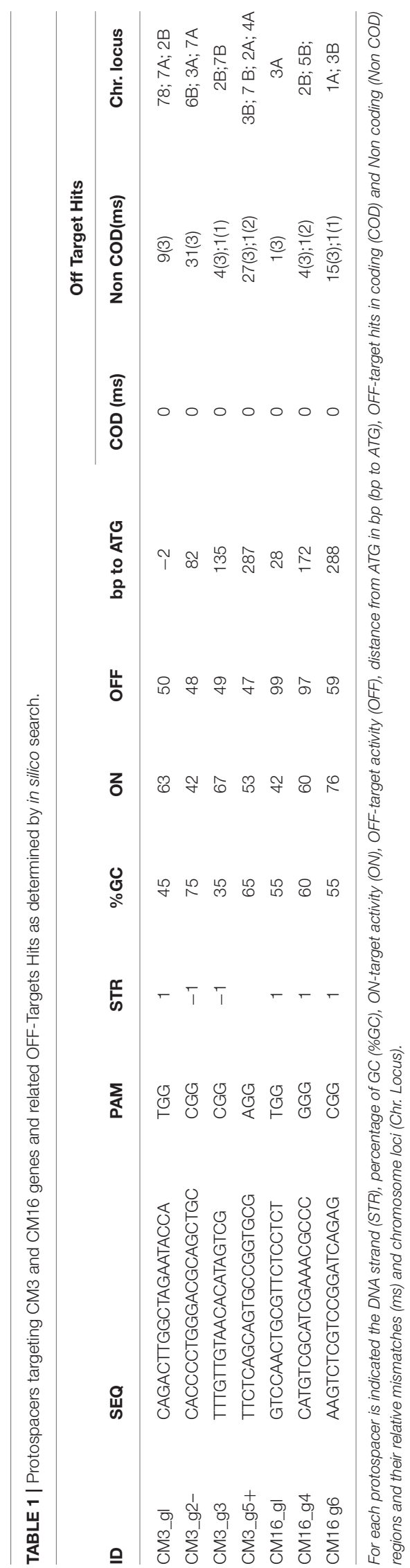

Frontiers in Sustainable Food Systems | www.frontiersin.org 
The GG product (pRRes208.482-PTG, Figure S1) was transformed into E. coli 10-beta competent cells (C3019H, NEB), according to manufacturer's instructions.

Plasmids were extracted with the Wizard SV Miniprep DNA purification System (Promega) and quantified using a Nanodrop spectrophotometer. The sequence of the final construct was confirmed by Sanger sequencing.

\section{Plant Material, Genetic Transformation, and Tissue Culture}

The durum wheat cultivar Svevo was used for biolistic transformation. Donor plants were grown in controlled environment rooms with an initial vernalisation at $4-5^{\circ} \mathrm{C}$ for 3 weeks, followed by $18-20^{\circ} \mathrm{C}$ day and $14-16^{\circ} \mathrm{C}$ night temperatures under a 16 -h photoperiod.

Plasmid vectors pRRes217.486 and pRRes208.482-PTG were co-bombarded into immature scutella of durum wheat cultivar Svevo, following Sparks and Jones (2014) except that the entire tissue culture and regeneration process was carried out without the use of selective agents, since no selectable marker gene was used in the transformation process. In brief, immature embryos were isolated from seeds 12-16 days post anthesis (DPA), the embryo axis was removed to prevent precocious germination and 30 scutella were placed with the uncut scutellum surface upwards within the central area of a 9-cm Petri dish containing induction medium. The isolated scutella were pre-cultured in the dark at $22^{\circ} \mathrm{C}$ for $1-2$ days prior to bombardment. The two plasmid vectors were coated onto $0.6 \mu \mathrm{m}$ gold particles (BioRad Laboratories Ltd., UK) in a 1:1 molar ratio and delivered using a Bio-Rad PDS1000/He particle bombardment system with a rupture pressure of 650 psi and vacuum of 28 " $\mathrm{Hg}$. Following bombardment, the scutella were spread between two plates of induction medium i.e., 15 scutella on each (Sparks and Jones, 2014). Plates were incubated in the dark at $22^{\circ} \mathrm{C}$ for 3-4 weeks to induce embryogenic callus. Calli which had developed somatic embryos were transferred to regeneration medium in $9-\mathrm{cm}$ Petri dishes and incubated at $22^{\circ} \mathrm{C}$ in the light for 3-4 weeks (Sparks and Jones, 2014). Responsive calli were transferred to regeneration medium without hormones in GA7 Magenta vessels (Sigma-Aldrich, UK) and cultured at $22^{\circ} \mathrm{C}$ in the light for 2-4 weeks. Regenerating plantlets were transferred to regeneration medium without hormones in GA-7 Magenta vessels (Sigma-Aldrich, UK) and potted to soil once sufficiently developed. Plants were grown to maturity in a GM containment glasshouse at $18-20^{\circ} \mathrm{C}$ day and $14-16^{\circ} \mathrm{C}$ night temperatures with a 16 -h photoperiod.

\section{DNA Extraction}

Genomic DNA was extracted from leaves of $T_{0}$ and $T_{1}$ plants and from half-seeds of $\mathrm{T}_{0}$ plants using NucleoSpin ${ }^{\circledR}$ Plant II (Macherey-Nagel) according to the manufacturer's instructions. The DNA was used as template for genotyping of regenerated plants and for detection of construct vectors.

\section{Screening for Large Mutations}

The presence of large deletions in the transformed plants was assessed by PCR. Two specific primer pairs (Table S2) encompassing the potential mutations induced by CRISPR-Cas9 were used to amplify 437 bp of CM3 gene and 451 bp of CM16 gene from DNA samples of plantlets, with the following reaction: $10 \mu \mathrm{l}$ of $2 \mathrm{X}$ GoTaq ${ }^{\circledR}$ G2 Hot Start Colorless Master Mix (Promega), $0.5 \mu \mathrm{M}$ of each primer, $20 \mathrm{ng}$ of template DNA and nuclease-free water to $20 \mu \mathrm{l}$ volume, with the following conditions: $95^{\circ} \mathrm{C}$ for $2 \mathrm{~min}$, followed by 35 cycles at $95^{\circ} \mathrm{C}$ for $1 \mathrm{~min}, 63^{\circ} \mathrm{C}$ for $30 \mathrm{~s}, 72^{\circ} \mathrm{C}$ for $45 \mathrm{~s}$ and a final extension at $72^{\circ} \mathrm{C}$ for $5 \mathrm{~min}$. PCR amplicons were assessed by electrophoresis using $2 \%$ agarose gel. Amplicons which demonstrated different mobility compared to the control were sequenced by Sanger sequencing.

\section{Screening for Small Mutations}

The High Resolution Melting (HRM) analysis was carried out on CM3 and CM16 gene fragments amplified from genomic DNA of $T_{0}$ plantlets in order to identify mutant plants carrying short insertion/deletions (IN/DELs) or single nucleotide polymorphisms (SNPs).

Amplicons suitable for HRM analysis were produced by a nested PCR strategy to obtain two short fragments per gene, using primer pairs reported in Table S2. The first PCR was carried out to amplify a $437 \mathrm{bp}$ fragment from the CM3 gene and a $451 \mathrm{bp}$ fragment from the CM16 gene. The reactions were performed in a $10 \mu \mathrm{l}$ volume using the protocol and PCR conditions described for the detection of large mutations.

The PCR reactions were diluted 60 -fold and $2 \mu 1$ were used as template for the nested PCR to produce the short fragment for analysis. The reactions were performed as previously described about the screening for large mutations. The reactions were overlaid with $10 \mu \mathrm{l}$ of mineral oil (Sigma-Aldrich M5904) and after the final extension step, PCR amplicons were denatured at $95^{\circ} \mathrm{C}$ for $30 \mathrm{~s}$ and reannealed at $25^{\circ} \mathrm{C}$ for $1 \mathrm{~min}$.

Following nested PCR, plates were analyzed in the Lightscanner instrument (Idaho Technology Inc., USA) and subjected to HRM analysis according to Tan et al. (2016). Samples with relative fluorescence differences $(|\Delta F|)>0.05$ with respect to the reference (Hofinger et al., 2009) were considered to be putative mutants thus the entire amplicons of the gene were re-amplified from DNA of each such individuals for Sanger sequencing.

\section{Tracking of Indels by Decomposition Analysis (TIDE)}

Mutant plants identified by HRM analysis and showing overlapping peaks after Sanger sequencing, were re-amplified with primer pairs reported in Table S2 and analyzed using the TIDE web tool (tide.deskgen.com) in order to assess the efficiency of gene editing resulting from NHEJ-mediated repair of the target loci (Brinkman et al., 2014). The PCR conditions for reamplification of longer fragments of CM3 and CM16 genes were: $95^{\circ} \mathrm{C}$ for $2 \mathrm{~min}$, followed by 35 cycles at $95^{\circ} \mathrm{C}$ for $1 \mathrm{~min}, 61.5^{\circ} \mathrm{C}$ for $30 \mathrm{~s}, 72^{\circ} \mathrm{C}$ for $1 \mathrm{~min}$ and $15 \mathrm{~s}$, and a final extension at $72^{\circ} \mathrm{C}$ for $5 \mathrm{~min}$. 


\section{Detection of Transgenes in Regenerated Plants}

The genomic DNA extracted from $\mathrm{T}_{0}$ and $\mathrm{T}_{1}$ plants was used as template for PCR to detect the presence of CRISPR constructs. The reactions were performed with five primer pairs (Table S3) and in a final volume of $20 \mu \mathrm{l}$ as follows: $10 \mu \mathrm{l}$ of $2 \mathrm{X}$ GoTaq ${ }^{\circledR}$ G2 Hot Start Colorless Master Mix (Promega), 0.5 $\mu \mathrm{M}$ of each primer, $20 \mathrm{ng}$ of template DNA and nuclease-free water to $20 \mu \mathrm{l}$ volume, with the following conditions: $95^{\circ} \mathrm{C}$ for $2 \mathrm{~min}$, followed by 35 cycles at $95^{\circ} \mathrm{C}$ for $1 \mathrm{~min}, 61^{\circ} \mathrm{C}$ for $30 \mathrm{~s}, 72^{\circ} \mathrm{C}$ for $1 \mathrm{~min}$ and a final extension at $72^{\circ} \mathrm{C}$ for $5 \mathrm{~min}$. PCR amplicons were visualized on $1.5 \%$ agarose gels to confirm the presence of the transgenes.

\section{Analysis of Off-Target Mutations}

The off-targets were predicted by DESKGEN Cloud for each gRNA targeting CM3 or CM16 genes. Furthermore, the seed sequences (12 nt upstream of the PAM) of each gRNA were blasted against Durum Wheat RefSeq Rel. 1.0 (http://d-data. interomics.eu) and searched among coding sequences, with a tolerance of up to three mismatches.

\section{Enzyme-Linked Immunosorbent Assay (ELISA)}

ELISA tests were performed for detecting differences in the expression of the WTAI-CM3 protein subunit in the albumin and globulin fraction $(\mathrm{A} / \mathrm{G})$ of seeds from two $\mathrm{T}_{1}$ edited lines and Svevo control plants. The WMAI-0.28 subunit expression was also investigated. The wells of microtiter plates (MaxiSorp, Nunc) were coated with $5 \mu \mathrm{g} / \mathrm{mL}$ of antigen in $50 \mathrm{mM}$ carbonate buffer ( $\mathrm{pH}$ 9.6) (corresponding to $\mathrm{KCl}$ protein fraction of $\mathrm{A} / \mathrm{G}$ extracted from each line) for 1 night at $4^{\circ} \mathrm{C}$. After three washes with PBS $0.05 \%$ Tween 20, the plates were blocked with PBSmilk $4 \%$ for $1 \mathrm{~h} 30 \mathrm{~min}$ at room temperature. The plates were washed three times with PBS-0.05\% Tween 20, and incubated for $1 \mathrm{~h} 30 \mathrm{~min}$ at room temperature with monoclonal antibodies raised against $\mathrm{CM} 3$ or 0.28 . The curves were obtained with a serial dilution of antibodies from 1:2 to 1:200000 in PBS. Goat antimouse IgG antibody $(\mathrm{H}+\mathrm{L})$ Horseradish peroxidase conjugate (BioRad \#1706516) diluted 1:3000 in PBS was incubated for $1 \mathrm{~h}$ at room temperature after three washes with PBS-0.05\% Tween 20. The colorimetric substrate (OPD, o-Phenylenediamine/ $\mathrm{H}_{2} \mathrm{O}_{2}$ ) in $50 \mathrm{mM}$ citrate buffer, $\mathrm{pH} 5.5$ was added for $30 \mathrm{~min}$ at room temperature in the dark. The OPD reaction was stopped with $\mathrm{H}_{2} \mathrm{SO}_{4} 4 \mathrm{~N}$ and read at $492 \mathrm{~nm}$. Each analysis was performed in duplicate and the average calculated.

\section{Extraction and Amplification of Expressed Genes}

Total RNA was extracted from immature caryopses of two $\mathrm{T}_{1}$ edited lines, B3725-17.8c and B3725-79a.8b along with the control (wild type) at 14 (DPA), using the Spectrum Plant Total RNA kit (Sigma-Aldrich, St. Louis, USA) following the manufacturer's instructions. First strand complementary DNA was synthesized from $1 \mu \mathrm{g}$ of total RNA per sample using the QuantiTect Reverse Transcription Kit (Qiagen, Hilden, Germany) according to the manufacturer's instructions. A semiquantitative RT-PCR experiment was carried out with three specific primer pairs for CM3, CM16, and 0.28 genes (listed in Table S2). The actin gene was used as reference gene. The reactions were prepared in a final volume of $15 \mu \mathrm{l}$, consisting of $7.5 \mu \mathrm{l} \mathrm{GoTaq}{ }^{\circledR}$ Hot Start Polymerase (Promega Corporation, Madison USA), $0.5 \mu \mathrm{M}$ of each primer and $1 \mu \mathrm{l}$ of cDNA, with PCR protocol: $95^{\circ} \mathrm{C}$ for $30 \mathrm{~s}$ and 35 cycles at $95^{\circ} \mathrm{C}$ for $10 \mathrm{~s}, 60^{\circ} \mathrm{C}$ for $25 \mathrm{~s}$ and $72^{\circ} \mathrm{C}$ for $15 \mathrm{~s}$. Three biological replicates per line were used for the reaction.

\section{RESULTS}

\section{CRISPR-Cas 9 Transformation in Durum Wheat}

To obtain $\mathrm{T}_{0}$ mutant plants for CM3 and CM16 genes in the durum wheat cultivar Svevo, we adopted the multiplex gene editing strategy originally reported by Xie et al. (2015). In order to disrupt the entire coding sequence of the target genes and thus to block transcription, 4 gRNAs targeting the CM3 gene and 3 gRNAs targeting the CM16 gene were synthesized in the PTG architecture (Figure S1), which was cloned into the vector pRRes208.482. In total, 7 gRNAs targeting the two genes of interest (Figure 1A) were assembled under the control of a single RNA polymerase III promoter and processed inside the cell, exploiting the tRNA processing system of the plant (Schiffer et al., 2002; Kruszka et al., 2003; Phizicky and Hopper, 2010). The modified GG assembly, which was improved by replacing the FokI sites at the $5^{\prime}$ and $3^{\prime}$ ends of the primers needed for amplification of the first and last DNA parts, enabled production of the PTG in a one-step and one tube reaction. In total, 400 embryos isolated from immature seeds of the durum wheat cultivar Svevo were co-bombarded with the plasmids pRRes217.486 and pRRes208.482-PTG. Ninety seven plants were regenerated, 14 of which carried different types of editing events involving IN/DELs and SNPs that cause mutations in CM3 and CM16 coding sequences.

\section{Mutation Detection and Genotyping}

Since gRNAs were designed to cause large mutations in CM3 and CM16 genes (Figure 1A), some editing events were clearly visible by gel electrophoresis of CM3 and CM16 genes amplified by PCR (Figure 1B). However, all the $\mathrm{T}_{0}$ regenerated plants were analyzed by HRM with the aim also to identify small IN/DELs and SNPs in the two-targeted genes (CM3 and CM16); the HRM analysis was conducted on two fragments per gene, amplified from genomic DNA of $\mathrm{T}_{0}$ plantlets. The nucleotide sequence of CM3 and CM16 genes of plants showing relative fluorescence differences $(|\Delta \mathrm{F}|)>0.05$ with respect to the reference were identified as potential mutants (Figure 1C) and thus genotyped through Sanger sequencing. The mutant samples that resulted in overlapping peaks based on Sanger sequencing were submitted to TIDE.

The screening resulted in identification of 14 genotypes carrying different types of editing events localized on the CM3 or CM16 genes, which included IN/DEL and SNP mutations (Table 2). In addition, the $\mathrm{T}_{0}$ plant B3725-14.7 showed mutations 
A

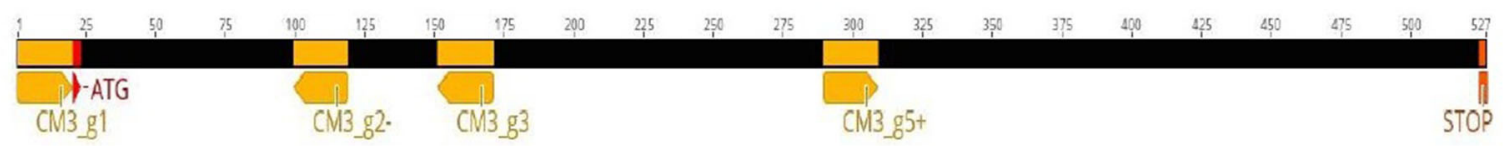

CM3

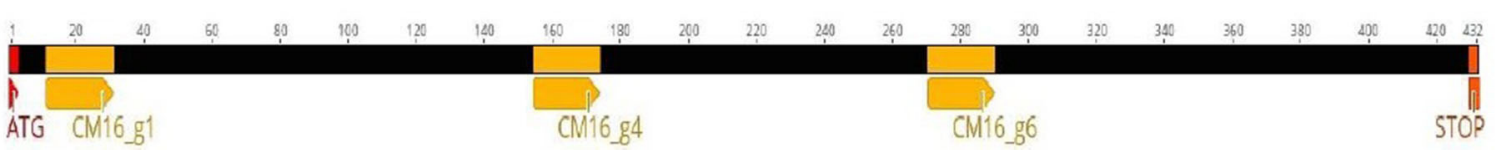

CM16

B
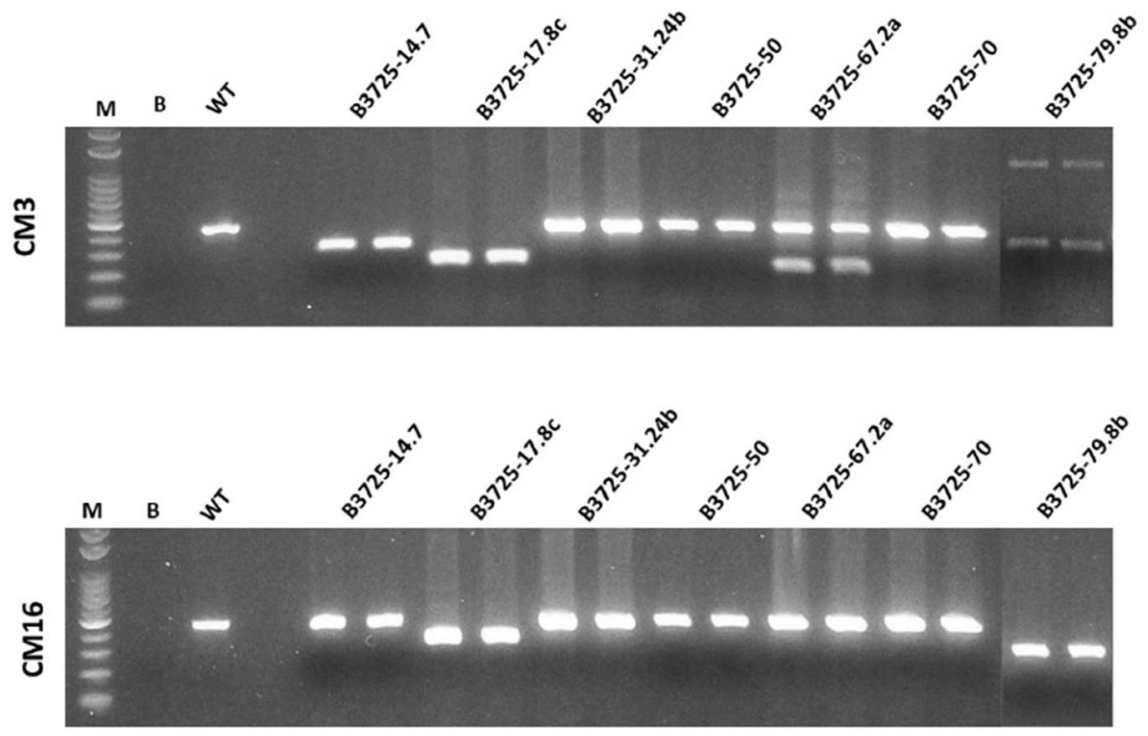

C
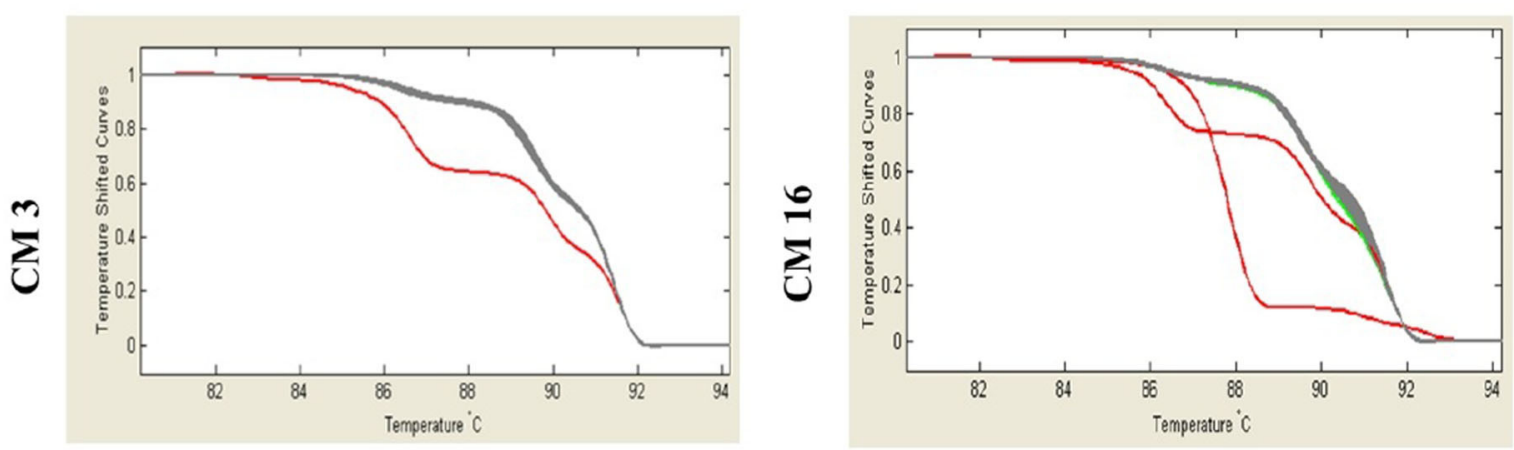

FIGURE 1 | Molecular analysis of CRISPR mutants. (A) Position and strand direction of gRNAs along CM3 and CM16 gene sequences, (B) PCR analysis of CM3 and CM16 mutants, (C) High Resolution Melt Curve, example of sharp decrease in fluorescence of mutants, gray = wild type, red = mutants.

in both $C M 3$ and $C M 16$ genes: two deletions of 4 and 116 bp were detected on $C M 3$ corresponding to editing by the CM3_g1 and CM3_g5+ guides (Figure 2A), whereas the CM16 gene sequence had one SNP in position 270 from the ATG (C -> G) close to the CM16_g6 guide (Figure 2B) which did not result in any amino acid change. 
TABLE 2 | Summary table of edited plants. Plants showing different types of editing events in CM3 and CM16 genes in the $T_{0}$ and $T_{1}$ generations.

\begin{tabular}{|c|c|c|c|c|c|c|c|c|c|c|}
\hline Plant ID & \multicolumn{3}{|c|}{$T_{0}$} & \multicolumn{3}{|c|}{$\mathrm{T}_{1}$} & \multicolumn{2}{|c|}{$T_{0}$} & \multicolumn{2}{|c|}{$T_{1}$} \\
\hline B3725-17.8c & 2 & DEL & IN/DEL & 2 & DEL & IN/DEL & $\sqrt{ }$ & & & \\
\hline B3725-31.24b & 1 & DEL & WT & 0 & WT & WT & & & & \\
\hline B3725-5la.3a & 2 & DEL & IN/DEL/SNP & 2 & DEL & IN/DEL/SNP & & & & \\
\hline B3725-5la Sa & 1 & DEL & WT & No seeds & & & & & & \\
\hline B3725-59.12b & 2 & DEL & SNP & 2 & DEL & SNP & $\sqrt{ }$ & $\sqrt{ }$ & & $\sqrt{ }$ \\
\hline B3725-67.2a & 2 & DEL & SNP & 2 & DEL/SNP & SNP & & & & \\
\hline B3725-79a8b & 2 & DEL & DEL & 2 & DEL & DEL & $\sqrt{ }$ & & & \\
\hline B3726-118.la & 1 & DEL & WT & No seeds & & & $\sqrt{ }$ & & & \\
\hline B3726-128.la & 1 & DEL & WT & 0 & WT & WT & & & & \\
\hline
\end{tabular}

gRNAs and Cas9 columns indicate plants which had integrated CRISPR vectors.

Similarly, the two genes were both targeted in the genotype B3725-17.8c. Two deletions were observed on the CM3 coding region; the first one ( $-2 \mathrm{bp}$ ) caused by CM3_g1 guide before the transcriptional start codon and the second one (205 bp) occurred between the CM3_g2- and CM3_g5+ guides (Figure 2A). The electrophoretic mobility of CM16 PCR amplicon from plant B3725-17.8c was clearly different with respect to the control (Figure 1A), but the Sanger sequencing did not give clear results due to the presence of overlapping peaks, meaning it was not possible to detect precise IN/DELs probably due to different types of deletions being present as biallelic mutations.

The plants B3725-31.24b and B3725-59.12b showed the same types of mutation for both CM3 and CM16 genes: 1 bp deletion on the CM3 gene sequence, localized 2 bp upstream of the PAM sequence of CM3_g1 guide, which caused a shifting of the reading frame, and one SNP in position $270(\mathrm{C}->\mathrm{G})$ on the CM16 gene of B3725-59.12b (Figures 2A,B), described above.

The $\mathrm{T}_{0}$ plants, B3725-51a.3a, B3725-51a.4a, B3725-51a.5a B3726-118.1a, B3725-128.1a, B3726-136.5b, and B3726-176.2a contained a 1-bp deletion in the CM3 gene sequence as described in B3725-31.24b and B3725-59.12b (Figure 2A) whereas the CM16 gene was unaffected, except for B3725-51a.3a, that showed a mutation. The Sanger sequencing of the CM16 gene obtained from the B3725-51a.3a plant showed two IN/DEL mutations of $1 \mathrm{bp}$ at positions 74 (insertion) and 194 (deletion) from the ATG and 4 SNPs along the gene sequence at positions 40 ( $\mathrm{G}->\mathrm{C}), 171$ (C -> T), $201(\mathrm{G}->\mathrm{A})$, and $270(\mathrm{C}->\mathrm{G})$ with respect to the wild type gene sequence (Figure $2 \mathrm{~B}$ ).

The TIDE analysis of CM3 PCR amplicon relative to plants B3725-51a.3a, B3725-51a.4a, B3725-51a.5a estimated the frequency of -46 bp deletion was $7 \%$ with $p<0.001(p=3.2 \mathrm{e}-05)$ and $R^{2}=0.94$, whereas for the plant B3726-118.1a the frequency of -4 bp deletion was $5.2 \%$ with $p=7.8 \mathrm{e}-10$ and $R^{2}=0.91$, along CM3 gene sequence.
An insertion of +2 bp was estimated with a frequency of $13.8 \%$ with $p=2.9 \mathrm{e}-27 R^{2}=0.93$ by TIDE along the CM16 gene sequence of B3726-118.1a. TIDE has also found a $-24 \mathrm{bp}$ deletion in $C M 3$ gene of B3726-176.2a plant with a frequency of $3.9 \%$ ( $p$ $\left.=0.00035, R^{2}=0.91\right)$ and a deletion of $-12 \mathrm{bp}$ in the CM16 genes with a frequency of $7.4 \%,\left(p=1.7 \mathrm{e}-12\right.$ and $\left.R^{2}=0.96\right)$.

The electrophoresis of the CM3 PCR amplicon obtained from the plant B3725-67.2a showed two bands with different mobility (Figure 1B). Each band was sequenced: the nucleotide sequence of the higher band contained the same deletion ( $-1 \mathrm{bp})$ identified in the genotype B3725-31.24b along with a SNP $(A->G)$ at position 10 from ATG causing the replacing of a Lysine with a Glutamic acid $(\mathrm{K}->\mathrm{E})$, whereas the lower band carried two deletions of 86 bp between CM3_g1 and CM3_g2- guides and 153 bp between CM3_g3 and CM3_g5+ guides (Figure 2A). The CM16 gene sequence of plant B3725-67.2a (Figure 2B) showed the SNP in position $270(\mathrm{C}->\mathrm{G})$ already reported above.

Large deletions were also detected in the two targeted genes of the B3725-79a.8b $\mathrm{T}_{0}$ plant: the CM3 gene sequence could not be entirely reconstructed from Sanger sequencing results (Figure 2A) and showed an unusual electrophoretic mobility (Figure 1B), probably due to the presence of chimeric or biallelic mutations. Otherwise, the CM16 gene sequence showed a deletion of -163 bp starting 11 bp upstream of the PAM sequence of CM16_g1 guide (Figure 2B).

The CM3 PCR amplicons of the B3726-190 plant showed deletions of $-46 \mathrm{bp}$, with a frequency of $13 \%$ ( $p=1.5 \mathrm{e}-87$ and $\left.R^{2}=0.90\right)$, when submitted to TIDE.

$\mathrm{T}_{1}$ plants showed a mutation framework quite similar to those observed in the $\mathrm{T}_{0}$ but not all the plants contained the same mutations observed in the $\mathrm{T}_{0}$ generation (Table 2). The frequency of mutation in the $\mathrm{T}_{0}$ was overestimated in some instances probably due to somatic mutations and chimeras (B3725-31.24b, B3725-51a.4a, B3725-128.1a, and B3725-136.5b). 
A

\begin{tabular}{|c|c|}
\hline B REF & ACTACACCAGCGAACCAGACTTGGCTAGAATACCATGGCGTGCAAGTCCAGCTGCAGCCTCCTCCTCTTGGCCGCCGTCCTGCTCTCCGTCTTGGCCGCTGCTTCCGCCTCCGG \\
\hline 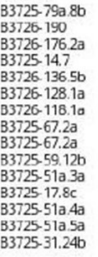 & 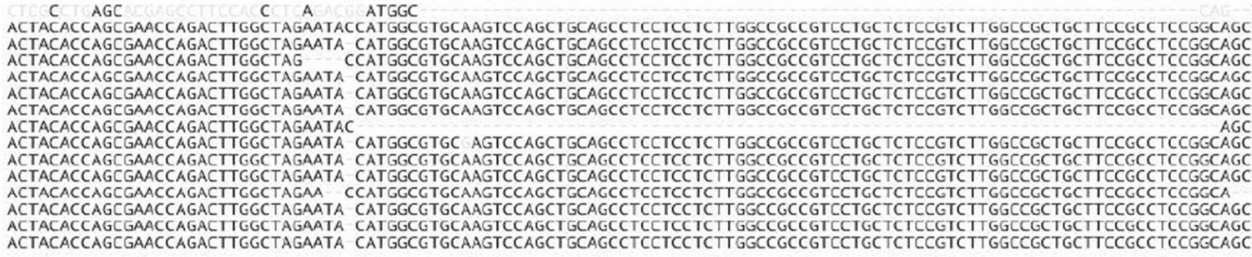 \\
\hline & CM3 33 \\
\hline 13REF & TACAACAAACTTGTGGCACCTTCACCCCCT \\
\hline 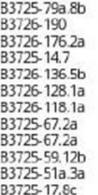 & 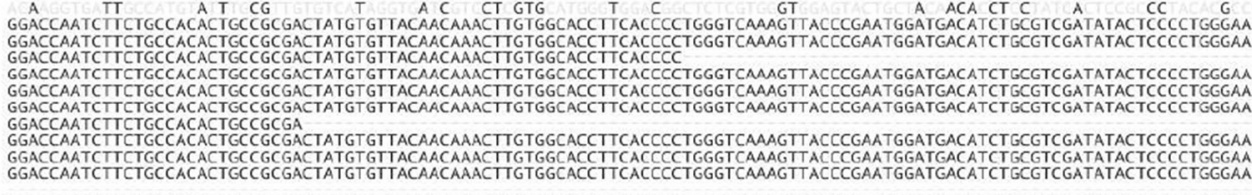 \\
\hline $\begin{array}{l}B 3725.51 a .4 a \\
B 3725.51 \mathrm{a} a \mathrm{a} \\
B 3725.31 .24 \mathrm{~b}\end{array}$ & $\begin{array}{l}\text { GGACCAATCTTCTGCCACACTGCCGCGACTATGTGITACAACAAACTTGGGGACCTTCACCCCTGGGTCAAGTTACCCGAATGGATGACATCTGCGTCGATATACTCCCC } \\
\text { GGACAATCITCTGCCACACTGCCGCGCTATGTGITACAACAAACIGTGGCACCTICACCCCIGGGTAAAGTIACCCGAATGGATGACATCTGCGTCGATATACTCCCC } \\
\text { GGACCAATCTTCTGCCACACTGCGGGACTATGTGTTACAACAAACTTGTGGCACCTTCACCCCTGGTCAAAGTTACCCGAATGGATGACATCTGCGTCGATATACTCCCC }\end{array}$ \\
\hline & CM3 g5+ \\
\hline 13 REF & TCAGCAGTGCCGGTGCGAGGCGCTGCGCTACTTCATAGCGTTGCCGGTACCGTCTCAGCCTGTGGACCCCG \\
\hline $\begin{array}{l}83725.79 \mathrm{a} .8 \mathrm{~b} \\
83726.190 \\
83726.176 .2 \mathrm{a}\end{array}$ & 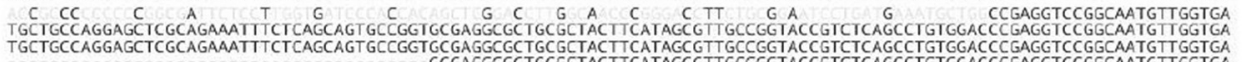 \\
\hline $\begin{array}{l}\text { B3725. } 14.7 \\
\text { B3726-136.5b } \\
\text { B3726-128.1a } \\
\text { B3726-118.1a } \\
\text { B3725.67.2a }\end{array}$ & $\begin{array}{l}\text { GC } \\
\text { TGCTCCCAGGAGCTCGCAGAAATTTCTCAGCAGTGCCGGTGC } \\
\text { TGCTGCCAGGAGCTCGCAGAAATTTCTCAGCAGTGCCGGTGC } \\
\text { TGCTECCAGGAGCTCGCAGAAATTTCTCAGCAGTGCCGGTGC }\end{array}$ \\
\hline $\begin{array}{l}\text { B3725.67.2a } \\
\text { B3725.59.12b } \\
B 3725.51 \mathrm{a} .3 \mathrm{a} \\
\mathrm{B} 3725.17 .8 \mathrm{c}\end{array}$ & $\begin{array}{l}\text { TGCTGCCAGGAGCTCGCAGAAATTTCTCAGCAGTGCCGGTGCGAGGCGCTGCGCTACTTCATAGCGTTGCCGGTA } \\
\text { TGCTGCCAGGAGCTCGCAGAAATTTCTCAGCAGTGCCGGTGCGAGGCGCTGCGCTACTTCATAGCGTTGCCGGTA } \\
\text { TGCTGCCAGGAGCTCGCAGAAATTTCTCAGCAGTGCCGGTGCGAGGCGCGGGCTACTTCATAGCGTTGCCGGGA } \\
\text { TGCGAGGCGCTGCGCTACTTCATACCGTTGCCGGTA }\end{array}$ \\
\hline $\begin{array}{l}\text { B } \\
B 3725.51 a .4 a \\
B 3725-51 a .5 a\end{array}$ & $\begin{array}{l}\text { GCAGTGCCGGTGCGAGGCGCTGCGCTACTTCATAGCGTTGCCGTACCGTCTCA A } \\
\text { GCAGTGCCGGTGCGAGCGCTGCGCIACTICATAGCGTIGGCGGTACCGICTCA }\end{array}$ \\
\hline $725.31 .24 \mathrm{~b}$ & CGGTGCGAGGCGCTGCGCTACTTCATAGCGTTGCCGGTACCGTCTCAGCCTGTGGACCCGAGGTCCGGCAATGTTGGT \\
\hline
\end{tabular}

B

CM16 REF ACAAATATGGCGTCCAAGTCCAACTGCGTTCTCCTCTTGGCCGCCGTCCTAGTCTCCATCTTTGCCGCCGTTGCCGCCA-TCGGCAATGAAGATTGCACCCCATGGATGAGTACTCT B3725-147 ACAAATATGGCGTCCAAGTCCAACTGCGTTCTCCTCTTGGCCGCCGTCCTAGTCTCCATCTTTGCCCGCCGTTGCCGCCA-TCGGCAATGAAGATTGCACCCCATGGATGAGTACTCT 83725-3124D
B3725-519.39 ACAATATGGCGTCCAAGTCAACTGCGTTCTCCTCTTGGCCGCCGTCCTAGTCTCCATCTTTGCCGCCGTTGCCGCCA-TCGGCAATGAAGATTGCACCCCATGGATGAGTACTCT
ACAATATGGCGTCCAGTCCAACTGCGTTCTCCTCTTGGCCGCC TCCTAGTCTCCATCTTTGCCGCCGTTGCGCCA TCGGCAATGAAGATTGCACCCCATGGATGAGTACTCT $83725-519.33$
$83725-793.83$ $83725-59.120$ $83725.672 \mathrm{a}$ B3725. 178 ATGGCGTCCAAGTCCAACT ACAAATATGGCGTCCAAGTCCAACTGCGTTCTCCTCTTGGCCGCCGTCCTAGTCTCCATCTTTGCCGCCGTTGCCGCCA-TCGGCAATGAAGATTGCACCCCATGGATGAGTACTCT ACAAATATGCGTCCAAGTCCAACTGCTTCTCCTCTTGGCCGCCGTCCTAGTCTCCATCTTGECGCCGTTGCCGCCA-TCGGCAATGAAGATTGCACCCCATGGATGAGTACTCT

CIM16 REF

B3725. 147.

B3725-31.24

B3725-51a.3

$83725.59 .12 b$
$83725-67.2 \mathrm{a}$

B3725-672a

GATCACTCCACTCCCAAGCTGCCGTGACTATGTGGAACAACAAGCATGTCGCATCGAAACGCCCGGGTCGCCGTACCTCGCCAAGCAGCAGTGCTGTGGGGAGCTTGCAAACATTCC GATCACTCCACTCCCAAGCTGCCGTGACTATGTGGAACAACAAGCATGTCGCATCGAAACGCCCGGGTCGCCGTACCTCGCCAAGCAGCAGTGCTGTGGGGAGCTTGCAAACATTCC GATCACTCCACTCCCAAGCTGCCGTGACTATGTGGAACACAAGCATGTCGCATCGAACGCCCGGGTCGCCGTACCTCGCCAAGCAGCAGTGCTGGGGGGAGCTTGCAACATTCC
GATCACTCCACTCCCAAGCTGCCGTGACTATGTGGACAACAAGCATGTCGCATCGAAA GCCCGGGTCGCCGTACCTCGCCA GCAGCA TGCTGTGGGGAGCTTGCAAACATTCC

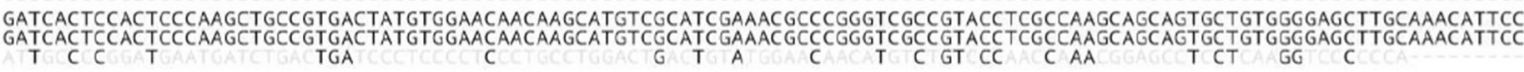

CM16 REF

${ }_{83725-312.240}^{8325}$

$83725-512.39$

B3725-79..80

B3725-59.12b
$83725-67.2 \mathrm{a}$
$B 3725-178 \mathrm{C}$

GCAGCAGTGCCGATGCCAGGCGCTGCGCTACTTCATGGGGCCGAAGTCTCGTCCGGATCAGAGCGGCCTCATGGAACTCCCCGGATGCCCTAGGGAGGTGCAGATGGACTTCGTG GCAGCAGTGCCGATGCCAGGCGCTGCGCTACTTCATGGGGCC AAGTCTCGTCCGGATCAGAGCGGCCTCATGGAACTCCCCGGATGCCCTAGGGAGGTGCAGATGGACTTCGTG GCAGCAGTGCCGATGCCAGGCGCTGCGCTACTTCATGGGGCCGAAGTCTCGTCCGGATCAGAGCGGCCTCATGGAACTCCCCGGATGCCCTAGGGAGGTGCAGATGGACTTCGTS GCAGCAGTGCCGATGCCAGGCGCTGCGCTACTTCATGGGGCC AAGTCTCGTCCGGATCAGAGCGGCCTCATGGAACTCCCGGATGCCCTAGGGAGGTGCAGATGGACTTCGTG GCAGCAGTGCCGATGCCAGGCGCTGCGCTACTTCATGGGGCC AAGTCTCGTCCGGATCAGAGCGGCCTCATGGAACTCCCGGATGCCCTAGGGAGGTGCAGATGGACTTCGTG
GCAGCAGTGCCGATGCCAGGCGCTGCGCTACTTCATGGGGCC AAGTCTCGTCGGATCAGAGCGGCTCATGGACTCCCCGGATGCCCTAGGGAGGTCAGATGACTTCGTG
G CCGAA
GGC

FIGURE 2 | Genotyping of $T_{0}$ CRISPR mutants. (A) Sanger sequencing of some representative CM3 mutants. (B) Sanger sequencing of some representative CM16 mutants. Gray arrow indicates gRNAs position and orientation. The light colored letters indicate different nucleotide compared to the reference sequences.

In addition, three $\mathrm{T}_{0}$ plants (B3725-51a.5a, B3726-118.1a, and B3726-190) failed to produce seeds consequently the heritability of the mutations could not be studied in these plants. The lines B3725-14.7, B3725-17.8c, B3725-51a.3a, B3725-59.12b, B372567.2a, and B3725-79a.8b showed stable and heritable mutations in the $\mathrm{T}_{1}$ generation. Interestingly, some $\mathrm{T}_{1}$ plants generated from the B3725-14.7 and B3725-67.2a $\mathrm{T}_{0}$ plants carried different types of mutation compared to the corresponding parents, in addition to the same type of mutation observed in the $\mathrm{T}_{0}$, indicating the putative transgenerational activity of Cas 9 and gRNAs and the segregation of biallelic and heterozygous mutations. $\mathrm{T}_{1}$ plants of the line B3725-14.7 showed a deletion in the CM16 gene of 141 bp ranging from 5 bp upstream of the PAM sequence of CM16_g1 guide to 7 bp upstream of CM16_g4 
guide in the $\mathrm{T}_{1}$ generation, whereas $\mathrm{B} 3725-67.2$ a produced plants with -1 bp deletion in the CM3 gene sequence 2 bp upstream of the PAM sequence of CM3_g1 guide and plants showing two deletions of 86 bp between CM3_g1 and CM3_g2- guides and 153 bp between CM3_g3 and CM3_g5+ guides. No mutations predicted by TIDE analysis were found in the $\mathrm{T}_{1}$ generation.

\section{Selection of Edited Plants Without CRISPR-Cas9 Vectors}

To assess the presence of CRISPR vectors in the regenerated mutant plants, PCRs were performed with primer pairs designed across the ubiquitin promoter region and gRNAs cassette for pRRes208.482 plasmid and across the Cas9 sequence and spectinomycin gene for pRRes217.486 plasmid, reported in Table S3. Both CRISPR vectors were absent in some $\mathrm{T}_{0}$ edited plants but the gRNAs vector was found more frequently with respect to Cas9 vector (Table 2). We have also studied the segregation of CRISPR constructs between generations: some lines which possessed the constructs in the $\mathrm{T}_{0}$ generation had lost them in the subsequent generation. Plants without mutations but showing the presence of both plasmid vectors were also selected and analyzed in the $\mathrm{T}_{1}$ generation in order to evaluate the transgenerational activity of Cas9 and gRNAs; no activity was detected in the corresponding $\mathrm{T}_{1}$ plants. The screening identified 4 mutant lines in the $\mathrm{T}_{1}$ generation (B3725-17.8c, B3725-51a.3a, B3725-67.2a, B3725-79a.8b), in which the two constructs were absent (Table 2).

\section{ELISA Assay for the Estimation of WTAI-CM3 and WMAI-0.28 Subunits Content}

In order to assess whether the $\mathrm{T}_{1}$ edited durum wheat lines contain different amounts of WTAI-CM3 subunits compared to the control, an indirect ELISA was performed using a monoclonal antibody against $\alpha$-amylase inhibitor CM3 subunit on an $A / G$ fraction extracted from wild type line and two $\mathrm{T}_{1}$ edited lines (Figure 3). The relative content of WTAI-CM16 was not assessed since no monoclonal antibody against WTAI-CM16 is available.

The lines B3725-17.8c and B3725-79a.8b were chosen for the ELISA test since they contain a homozygous mutation for both targeted genes in the form of a large deletion. The ELISA analysis revealed no reactivity of the $A / G$ fraction extracted from the lines B3725-17.8c and B3725-79.8b with the primary monoclonal antibody against WTAI-CM3 (Figure 3A), confirming that mutations caused a gene knockout.

As expected, ELISA tests performed by using the antibody against WMAI-0.28 (Figure 3B), showed that WT control Svevo did not show any significant reactivity, since the 0.28 gene is encoded on the $\mathrm{D}$ genome, which is absent in durum wheat, and the 0.28 gene, present on chromosome $6 \mathrm{~B}$ of durum wheat, is actually a pseudogene (TRITD6Bv1G000060.1). Surprisingly, all the protein fractions extracted from the two edited lines, reacted with the 0.28 antibody. We hypothesized that this could be due to the activation of the 0.28 pseudogene as a pleiotropic effect due to the knockout of the two target genes. Expression analysis of target genes was therefore performed as reported below, the results of which support this hypothesis.

\section{Comparison of ATI Gene Expression Between Mutant Lines and Wild Type}

In order to investigate the presence of CM3, CM16, and 0.28 transcripts, gene amplification was carried out on cDNA derived from RNA extracted from the immature seeds of the most interesting $\mathrm{T}_{1}$ edited lines: B3725-17.8c and B3725-79a.8b (Figure 4). In particular, line B3725-79a.8b shows no band corresponding to the CM3 transcript and only a faint band of smaller size (about $150 \mathrm{bp}$ ) compared to the control (about $400 \mathrm{bp}$ ) corresponding to the CM16 transcript. Similarly, the transcripts of the line B3725-17.8c produced weak bands for both genes which were smaller than the control (200 vs. $400 \mathrm{bp}$ and 300 vs. $400 \mathrm{bp}$, for CM3 and CM16 genes, respectively).

Since the edited lines reacted against the 0.28 antibody in the ELISA assay, the expression of the 0.28 gene was investigated; the band corresponding to the 0.28 transcript was consistently present in the edited lines whereas it was completely absent in the WT. The 0.28 amplification product of the B3725-17.8c and B3725-79a.8b lines was sequenced and found to correspond to the 0.28 homoeologous gene present on the $6 \mathrm{~B}$ chromosome, which contains 16 SNPs (10 transitions and 6 transversions), but which encodes for the same mature protein encoded by the 0.28 gene on chromosome 6D (Figure S2).

\section{Detection of Potential Off-Targets}

No off-targets were predicted or detected by in silico analysis in coding regions of the bread wheat reference genome. The in silico search for off-target sites was expanded to the whole genome of durum wheat by searching for perfect matches of the gRNA seed sequence (12 nt) plus PAM in the reference genome of durum wheat (Maccaferri et al., 2019). All gRNAs did not target any annotated genes of Durum Wheat RefSeq Rel. 1.0 but few targets in non-coding regions with 1-3 mismatches were found (Table 1).

\section{DISCUSSION}

Breeding programmes focused on the removal or reduction of ATI proteins have not been developed in wheat yet, either because wheat allergies due to this class of proteins are not very common in the general population or perhaps because they are encoded by several genes that make the classical breeding approaches time consuming and not totally effective. The possible involvement of ATI in NCWS, that is claimed to affect at least $10 \%$ of the Western human population, makes this breeding goal important.

The development of novel strategies, such as the genome editing, offers new opportunities to manipulate the expression of gene families. In particular, in the last 5 years, the CRISPR-Cas9based genome editing technology has become the predominant new breeding technique for crop breeding, not only for agronomic targets, but also for the development of new genotypes that can be considered safer in terms of health aspects (SánchezLeón et al., 2018; Jouanin et al., 2019). Furthermore, CRISPR tools have received a great deal of attention for crop breeding 
A

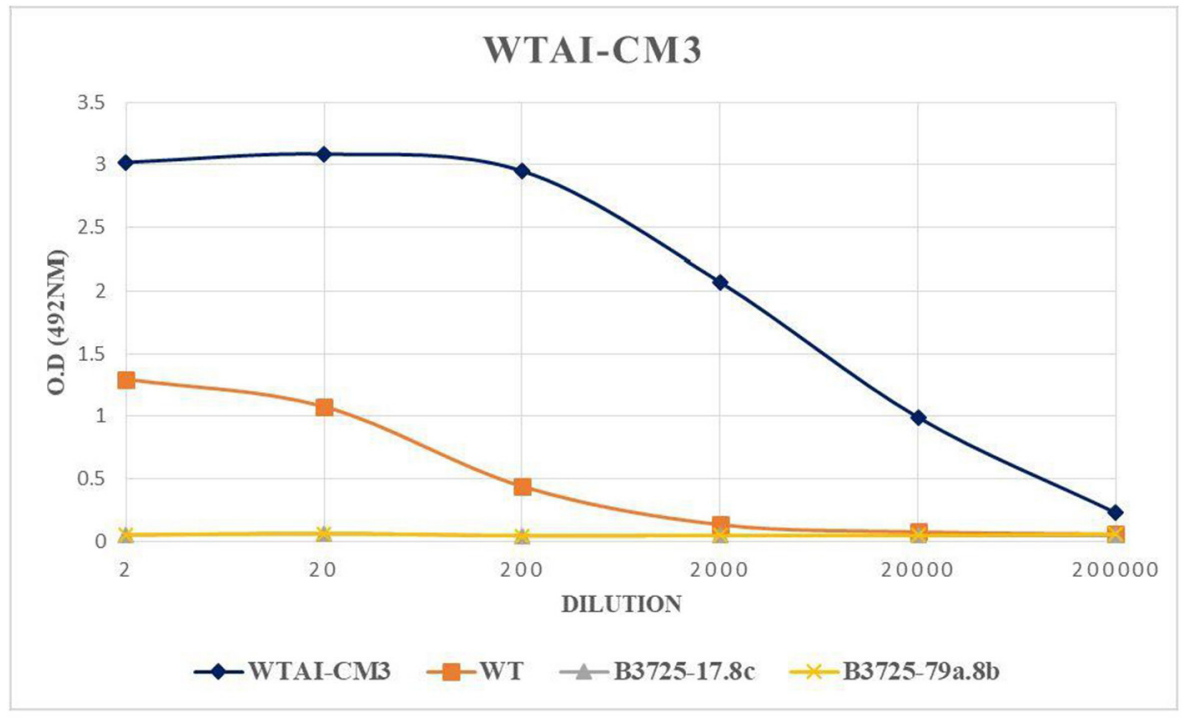

B

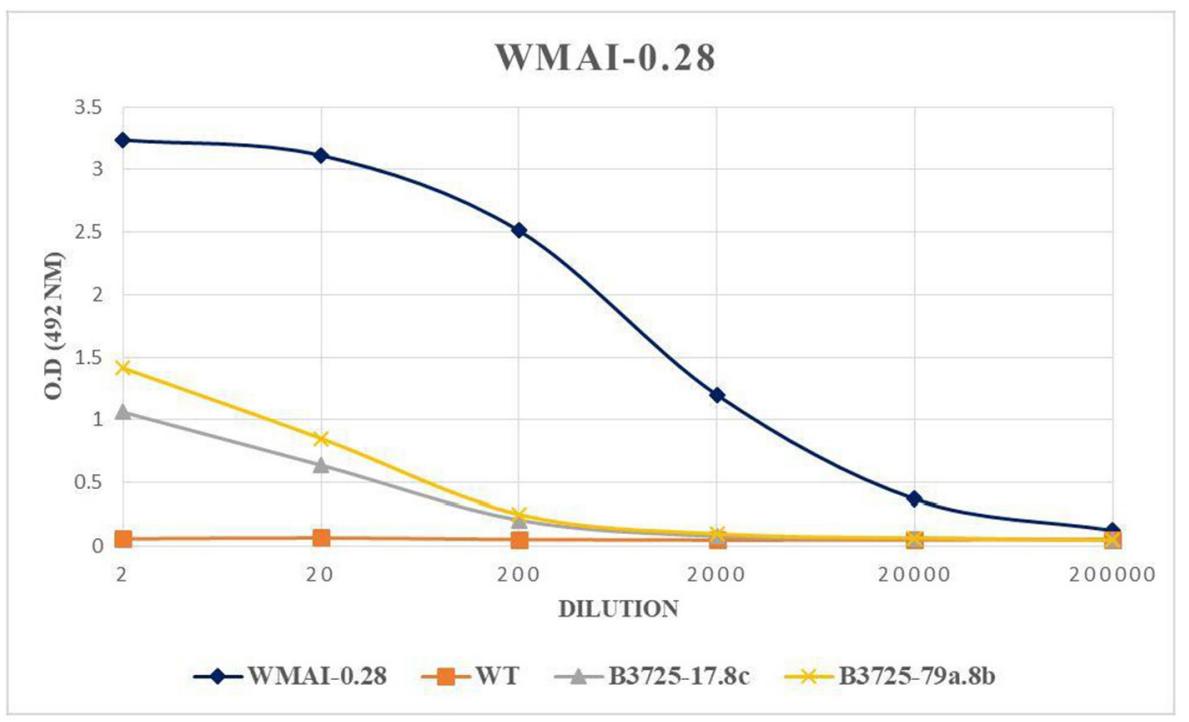

FIGURE 3 | ELISA-test performed with monoclonal antibody against WTAI-CM3 (A) and WMAl-0.28 (B) subunits present in the A/G fraction of $T_{1}$ Svevo control plants and the two edited lines obtained by CRISPR-Cas9. WTAI-CM3 and WMAl-028 correspond to purified proteins, WT to Svevo control plants.

because of its main features: the high efficiency and accuracy of gene editing, the multiplexing capability (Baltes and Voytas, 2015; Xie et al., 2015; Tang et al., 2019), the minimized chance of off-target mutations and the possibility to obtain transgenefree mutant plants in the first generation (Zhang et al., 2016) that make them non GMO, although this is still a matter of debate at legislative level.

In this paper, we used a multiplex genome editing strategy to target simultaneously two ATI genes (CM3 and CM16) in durum wheat, both indicated as major allergens in bread and durum wheat (Zevallos et al., 2017; Tundo et al., 2018; Bellinghausen et al., 2019), and likely to be involved in NCWS.

The use of multiple guides targeting each gene allowed us to obtain some lines with large deletions, notably, four lines (B3725-17.8c, B3725-51.3a, B3725-67.2a, and B3725-79a.8b) which showed large deletions in the CM3 gene and two of these lines (B3725-17.8c and B3725-79a.8b) which also contained large deletions in the CM16 gene. The strategy to introduce 

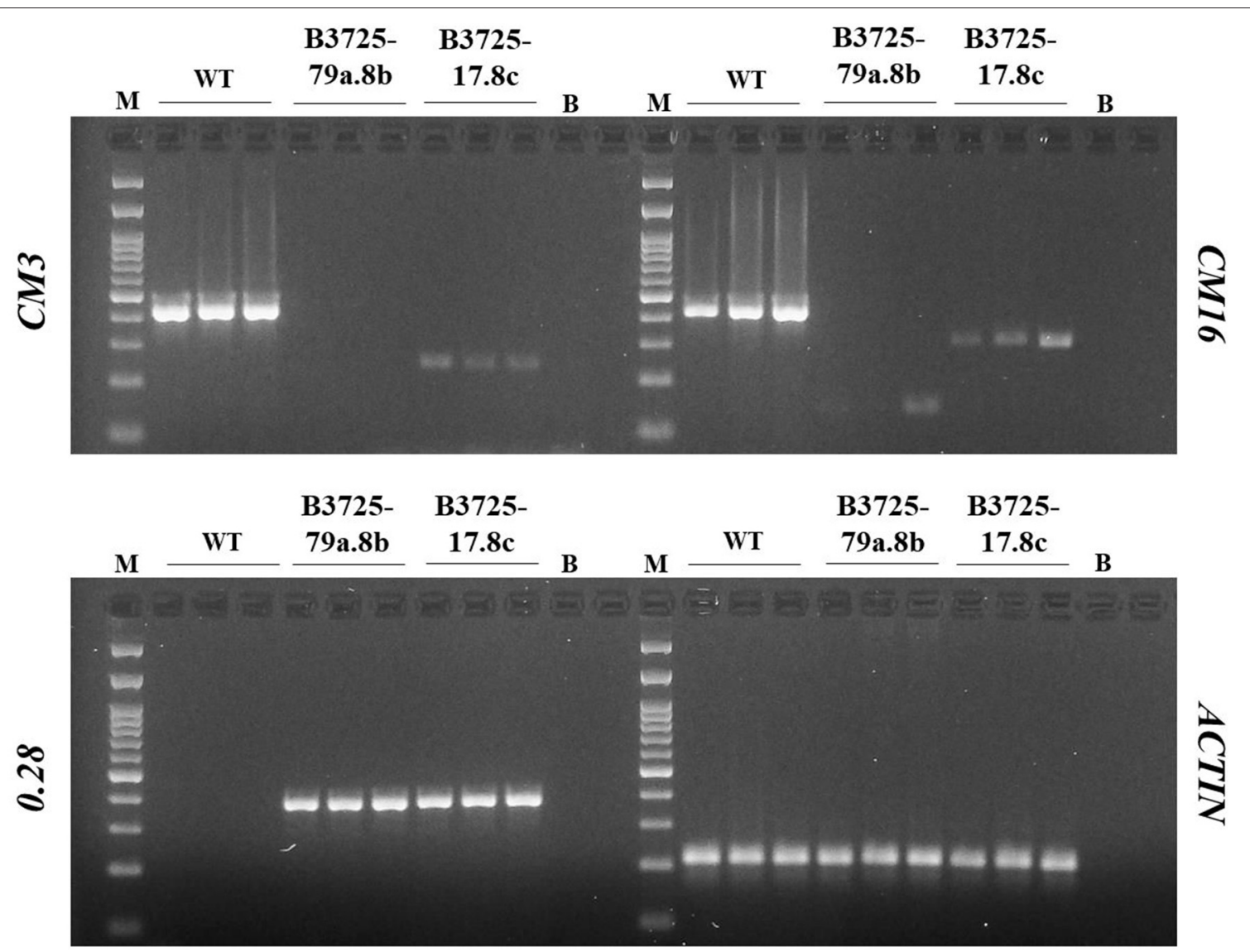

FIGURE 4 | PCR amplicon electrophoresis of expressed CM3, CM16, 0.28, and Actin genes. The outcome of PCR assays analyzing CM3, CM16, and 0.28 transcripts. M, molecular weight marker, 100 bp DNA ladder.

large deletions has two advantages: (1) the consequential loss of function of the edited gene and (2) the possibility to detect the mutants through inexpensive methods such as PCR and electrophoresis. Although large deletions were the most frequent mutations, HRM analysis allowed identification of SNPs and small deletions (1-4 bp). Similar types of edits were observed by other authors that used CRISPR/Cas9-based genome editing technology to supress genes of interest in the major cereal crops (rice, wheat, maize and barley) (Shan et al., 2014; Svitashev et al., 2015; Zhu et al., 2017; Howells et al., 2018; Kim et al., 2018; Li et al., 2018, 2019; Wang et al., 2018; Brauer et al., 2020). Although different gRNAs specific for each gene were used, we have not been able to observe substantial differences in the efficiency of each gRNA.

The majority of mutant plants showed homozygous mutations either for the CM3 (B3725-14.7, B3725-17.8c, B3725-79a.8b, B3726-118.1a, and B3726-176.2a) or CM16 gene (B3725-17.8c, B3725-31.24b, B3725-67.2a, and B3725-79a.8b). However, some mutant genotypes carried putative biallelic mutations in one or both of the targeted genes, probably due to lower expression of gRNAs or Cas9 cassettes.

Plants identified by TIDE as carrying mutations, did not demonstrate the predicted mutation in the $\mathrm{T}_{1}$ generation. This may be attribute to the occurrence of somatic mutation, besides some plants did not produce seeds.

These data confirmed that the multiplex genome editing system is an effective strategy to supress simultaneously more than one gene. A similar strategy has been used to target two or more genes in wheat, rice and maize (Xie et al., 2015; Qi et al., 2016; Wang et al., 2018).

In the $\mathrm{T}_{1}$ generation, we noticed an overestimation of $\mathrm{T}_{0}$ mutation frequency due to several factors affecting gene editing events. In some cases, somatic mutations were detected due to the activity of Cas9 and gRNAs in non-germ line cells which are not passed to the next generation, but transient expression of CRISPR vectors can also lead to mosaicism (Arora and Narula, 2017; Mehravar et al., 2019). Interestingly, we observed transgenerational activity of Cas9 and gRNAs vectors in two plants B3725-14.7 and B3725-67.2a, which showed mutation in $\mathrm{T}_{0}$. However, no transgenerational activity was found in selected plants which did not show editing events in the $\mathrm{T}_{0}$ generation, but which had integrated the CRISPR vectors.

The regeneration of plants without selection genes allowed the generation of some mutant lines without the presence of CRISPR vectors already in the $\mathrm{T}_{0}$ generation. Notably, the lines B3725-17.8c, B3725-51a.3a, and B3725-79a.8b containing large 
deletions in both CM3 and CM16 genes did not demonstrate the presence of Cas9 vector in the $\mathrm{T}_{0}$ generation or the gRNAs vector in the $T_{1}$ generation. We followed the strategy used by Zhang et al. (2016) to obtain transgene-free edited plants through a transient expression-based genome-editing system that allowed production of transgene-free, homozygous wheat mutants in the $\mathrm{T}_{0}$ generation.

The $A / G$ fraction extracted from two $T_{1}$ edited durum wheat lines (B3725-17.8c and B3725-79a.8b) showed no response to the anti WTAI-CM3 monoclonal antibody, indicating a total absence of the CM $3 \alpha$-amylase inhibitor subunit in the metabolic fraction (Figure 3A).

Since the CM16 gene transcript of B3725-17.8c and B372579a.8b appeared completely altered (Figure 2B), no functional proteins are expected in these lines. However, the relative content of WTAI-CM16 was not assessed since no monoclonal antibody against WTAI-CM16 is available, thus it was not possible to confirm experimentally the effect of the alteration on its expression.

Very interesting was the observation that the 0.28 pseudogene on the $6 \mathrm{~B}$ chromosome was activated in the edited lines, although the mechanism for this is not known. It is common in durum and bread wheat that the silencing of one member of a gene family can cause the overexpression of other members of the same gene family, as previously reported for gliadins (Camerlengo et al., 2017; Sánchez-León et al., 2018) but as yet this has not been described for ATI genes. Differently, wheat lines harboring compromised ATI genes showed a reduced level of targeted ATI transcripts. The origin of this reduction is probably due to the nonsense mediated mRNA decay mechanism, which imposes a measure of control over mRNA quality, and inhibits the formation of non-functional translation products (Baker and Parker, 2004; Behm-Ansmant et al., 2007).

Homozygous, transgene-free wheat lines edited for the CM3 and CM16 genes were obtained in the $\mathrm{T}_{0}$ generation, demonstrating the capability of CRISPR-Cas9 technology to produce improved wheat lines in a reduced time compared to conventional breeding and with substantial equivalence to their parental line. The editing events led to the knockout of these two genes in the durum wheat cultivar Svevo, thus representing a promising starting material for producing a safer, less allergenic wheat variety.

No off-target effects were predicted by DESKGEN Cloud in the coding region of the A and B genome of the Chinese Spring reference sequence and no hits were found when blasting the core sequence of each gRNA against the reference sequence of durum wheat $\mathrm{cv}$. Svevo, taking into account the coding regions.

In conclusion, we obtained three durum wheat lines (B372517.8c, B3725-51a.3a, and B3725-79a.8b) that contained stable and heritable mutations in the form of deletions in both genes of interest, CM3 and CM16. Two of these lines (B3725-17.8c and $B 3725-79 \mathrm{a} .8 \mathrm{~b}$ ) represent the most promising edited lines since they showed large deletions in both genes of interest and no reaction against WTAI-CM3 monoclonal antibody, therefore these will continue to be studied in subsequent generations either for in vitro or in vivo studies.

In another paper from our group (Kalunke et al., 2020), the same ATI genes, plus the 0.28 gene, were silenced in the bread wheat cultivar Bobwhite by using RNAi. Different parameters related to yield resulted not affected, although one related to dough quality was strongly affected due to the lower expression of high molecular weight glutenin subunits, as an unpredictable effect likely due to RNAi procedure. In this case, the proteomic analysis has not revealed a decreasing of gluten proteins, related to dough quality, and although in this paper, the effect of the ATI silencing on semolina quality has been not investigated; in future perspective these lines will be useful to assess if this fraction contributes to the cooking quality of pasta (Shewry, 2019). Moreover, it will be necessary to test if the silenced lines are more susceptible to pathogens during germination, since ATI proteins are involved in protection from insect, mite, and mammalian $\alpha$-amylases.

Since we transformed an elite durum wheat variety, the edited plants have potential to be grown as safer durum wheat lines for individuals predisposed to bakers' asthma, food allergies, and NCWS. In addition, they could be useful wheat genotypes to test ATI subunits implicated in those pathologies for which the triggering factor, as yet not been established. This material could be also used for plant breeding programmes for the introgression of hypoallergenic or less immunogenic traits into other elite wheat varieties.

\section{DATA AVAILABILITY STATEMENT}

The datasets presented in this article are not readily available because we do not have datasets, but original experimental data are available on request. Requests to access the datasets should be directed to Francesco Sestili, francescosestili@unitus.it.

\section{AUTHOR CONTRIBUTIONS}

FC performed the great majority of the analytical work. AF performed expression analysis. CS, AD, and DM coordinated wheat transformation and related analyses. RL and CL carried out ELISA tests. FS and SM conceptualized and supervised the work. FC and FS wrote most of the manuscript. All authors wrote parts of the manuscript, reviewed and edited it.

\section{FUNDING}

CS, DM, and AD (Rothamsted Research) received grant-aided support from the Biotechnology and Biological Sciences Research Council (BBSRC) of the UK as part of the 20:20 Wheat ${ }^{\circledR}$ Programme. FC mobility was funded in part by CIB (Italian Interuniversity Consortium for Biotechnologies). The research was carried out in the frame of the initiative Departments of excellence (Law 232/2016) of MIUR (Italian Minister for Education, University and Research).

\section{SUPPLEMENTARY MATERIAL}

The Supplementary Material for this article can be found online at: https://www.frontiersin.org/articles/10.3389/fsufs. 2020.00104/full\#supplementary-material 


\section{REFERENCES}

Altenbach, S. B., Vensel, W. H., and Dupont, F. M. (2011). The spectrum of low molecular weight alpha-amylase/protease inhibitor genes expressed in the US bread wheat cultivar Butte 86. BMC Res. Notes 4:242. doi: 10.1186/1756-0500-4-242

Arora, L., and Narula, A. (2017). Gene editing and crop improvement using CRISPR-Cas9 system. Front. Plant Sci. 8:1932. doi: 10.3389/fpls.2017.01932

Baker, K. E., and Parker, R. (2004). Nonsense-mediated mRNA decay: terminating erroneous gene expression. Curr. Opin. Cell Biol. 16, 293-299. doi: 10.1016/j.ceb.2004.03.003

Baltes, N. J., and Voytas, D. F. (2015). Enabling plant synthetic biology through genome engineering. Trends Biotechnol. 33, 120-131. doi: 10.1016/j.tibtech.2014.11.008

Battais, F., Richard, C., Jacquenet, S., Denery-Papini, S., and Moneret-Vautrin, D. A. (2008). Wheat grain allergies: an update on wheat allergens. Eur. Ann. Allergy Clin. Immunol. 40, 67-76.

Behm-Ansmant, I., Kashima, I., Rehwinkel, J., Sauliere, J., Wittkopp, N., and Izaur-ralde, E. (2007). mRNA quality control: an ancient machinery recognizes and degrades mRNAs with nonsense codons. FEBS Lett. 581, 2845-2853. doi: 10.1016/j.febslet.2007.05.027

Bellinghausen, I., Weigmann, B., Zevallos, V., Maxeiner, J., Reißig, S., Waisman, A., et al. (2019). Wheat amylase-trypsin inhibitors exacerbate intestinal and airway allergic immune responses in humanized mice. J. Allergy Clin. Immunol. 143, 201-212. doi: 10.1016/j.jaci.2018.02.041

Bhowmik, P., Ellison, E., Polley, B., Bollina, V., Kulkarni, M., Ghanbarnia, K., et al. (2018). Targeted mutagenesis in wheat microspores using CRISPR/Cas9. Sci. Rep. 8:6502. doi: 10.1038/s41598-018-24690-8

Brauer, E. K., Balcerzak, M., Rocheleau, H., Leung, W., Schernthaner, J., Subramaniam, R., et al. (2020). Genome editing of a deoxynivalenol-induced transcription factor confers resistance to fusarium graminearum in wheat. Mol. Plant. Microbe. 33, 553-560. doi: 10.1094/MPMI-11-19-0332-R

Brinkman, E. K., Chen, T., Amendola, M., and van Steensel, B. (2014). Easy quantitative assessment of genome editing by sequence trace decomposition. Nucleic Acids Res. 42:e168. doi: 10.1093/nar/gku936

Cabanillas, B. (2019). Gluten-related disorders: celiac disease, wheat allergy, and nonceliac gluten sensitivity. Crit. Rev. Food Sci. Nutr. 12, 1-16. doi: 10.1080/10408398.2019.1651689

Camerlengo, F., Sestili, F., Silvestri, M., Colaprico, G., Margiotta, B., Ruggeri, R., et al. (2017). Production and molecular characterization of bread wheat lines with reduced amount of $\alpha$-type gliadins. BMC Plant Biol. 17:248. doi: $10.1186 / \mathrm{s} 12870-017-1211-3$

Capocchi, A., Muccilli, V., Cunsolo, V., Saletti, R., Foti, S., and Fontanini, D. (2013). A heterotetrameric alpha-amylase inhibitor from emmer (Triticum dicoccon Schrank) seeds. Phytochemistry 88, 6-14. doi: 10.1016/j.phytochem.2012.12.010

Carbonero, P., and Garcì-Olmedo, F. A. (1999). "A multigene family of trypsin/aamylase inhibitors from cereals", in Seed Proteins eds. PR Shewry and R. Casey (Springer, Dordrecht). doi: 10.1007/978-94-011-4431-5_26

Dupont, F. M., Vensel, W. H., Tanaka, C. K., Hurkman, W. J., and Altenbach, S. B. (2011). Deciphering the complexities of the wheat flour proteome using quantitative two-dimensional electrophoresis, three proteases and tandem mass spectrometry. Proteome Sci. 9:10. doi: 10.1186/1477-5956-9-10

García-Maroto, F., Carbonero, P., and García-Olmedo, F. (1991). Site-directed mutagenesis and expression in Escherichia coli of WMAI-1, a wheat monomeric inhibitor of insect $\alpha$-amylase. Plant Mol. Biol. 17, 1005-1011. doi: 10.1007/BF00037140

García-Maroto, F., Maraña, C., Mena, M., García-Olmedo, F., and Carbonero, P. (1990). Cloning of cDNA and chromosomal location of genes encoding the three types of subunits of the wheat tetrameric inhibitor of insect $\alpha$-amylase. Plant Mol. Biol. 14, 845-853. doi: 10.1007/BF00016517

Gil-Humanes, J., Wang, Y., Liang, Z., Shan, Q., Ozuna, C. V., Sánchez-León, S., et al. (2017). High-efficiency gene targeting in hexaploid wheat using DNA replicons and CRISPR/Cas9. Plant J. 89, 1251-1262. doi: 10.1111/tpj.13446

Gu, A., Hao, P., Lv, D., Zhen, S., Bian, Y., Ma, C., et al. (2015). Integrated proteome analysis of the wheat embryo and endosperm reveals central metabolic changes involved in the water deficit response during grain development. J. Agric. Food. Chem. 63, 8478-8487. doi: 10.1021/acs.jafc.5b00575
Hamada, H., Liu, Y., Nagira, Y., Miki, R., Taoka, N., and Imai, R. (2018). Biolisticdelivery-based transient CRISPR/Cas9 expression enables in planta genome editing in wheat. Sci. Rep. 8:14422. doi: 10.1038/s41598-018-32714-6

Henggeler, J. C., Veríssimo, M., and Ramos, F. (2017). Non-coeliac gluten sensitivity: a review of the literature. Trends Food Sci. Technol. 66, 84-92. doi: 10.1016/j.tifs.2017.05.018

Hofinger, B. J., Jing, H. C., Hammond, K. E., and Kanyuka, K. (2009). Highresolution melting analysis of cDNA-derived PCR amplicons for rapid and cost-effective identification of novel alleles in barley. Theor. Appl. Genet. 119, 851-865. doi: 10.1007/s00122-009-1094-2

Howells, R. M., Craze, M., Bowden, S., and Wallington, E. J. (2018). Efficient generation of stable, heritable gene edits in wheat using CRISPR/Cas9. BMC Plant Biol. 18:215. doi: 10.1186/s12870-018-1433-z

Jouanin, A., Schaart, J. G., Boyd, L. A., Cockram, J., Leigh, F. J., Bates, R., et al. (2019). Outlook for coeliac disease patients: towards bread wheat with hypoimmunogenic gluten by gene editing of $\alpha$-and $\gamma$-gliadin gene families. BMC Plant Biol. 19:333. doi: 10.1186/s12870-019-1889-5

Junker, Y., Zeissig, S., Kim, S. J., Barisani, D., Wieser, H., Leffler, D. A., et al. (2012). Wheat amylase trypsin inhibitors drive intestinal inflammation via activation of toll-like receptor 4. J. Exp. Med. 209, 2395-2408. doi: 10.1084/jem.201 02660

Kalunke, R. M., Tundo S., Sestili F., Camerlengo F., Lafiandra D., Lupi R., et al. (2020). Reduction of allergenic potential in bread wheat RNAi transgenic lines silenced for CM3, CM16 and 0.28 ATI genes. Preprint. doi: 10.20944/preprints202007.0581.v1

Kim, D., Alptekin, B., and Budak, H. (2018). CRISPR/Cas9 genome editing in wheat. Funct. Integr. Genomic. 18, 31-41. doi: 10.1007/s10142-0170572-x

Kruszka, K., Barneche, F., Guyot, R., Ailhas, J., Meneau, I., Schiffer, S., et al., (2003). Plant dicistronic tRNA-snoRNA genes: a new mode of expression of the small nucleolar RNAs processed by RNase Z. EMBO J. 22, 621-632. doi: $10.1093 / \mathrm{emboj} / \mathrm{cdg} 040$

Kumar, R., Kaur, A., Pandey, A., Mamrutha, H. M., and Singh, G. P. (2019). CRISPR-based genome editing in wheat: a comprehensive review and future prospects. Mol. Biol. Rep. 46, 3557-3569. doi: 10.1007/s11033-019-0 4761-3

Kusaba-Nakayama, M., Ki, M., Kawada, E., Sato, M., Ikeda, I., Mochizuki, T., et al. (2001). Intestinal absorbability of wheat allergens, subunits of a wheat $\alpha$-amylase inhibitor, expressed by bacteria. Biosci. Biotechnol. Biochem. 65 , 2448-2455. doi: 10.1271/bbb.65.2448

Li, C., Nguyen, V., Liu, J., Fu, W., Chen, C., Yu, K., et al. (2019). Mutagenesis of seed storage protein genes in Soybean using CRISPR/Cas9. BMC Res. Notes 12:176. doi: 10.1186/s13104-019-4207-2

Li, S., Zhang, X., Wang, W., Guo, X., Wu, Z., Du, W., et al. (2018). Expanding the scope of CRISPR/Cpf1-mediated genome editing in rice. Mol. Plant 11, 995-998. doi: 10.1016/j.molp.2018.03.009

Liang, Z., Chen, K., and Gao, C. (2019). "Biolistic delivery of CRISPR/Cas9 with ribonucleoprotein complex in wheat", in Plant Genome Editing with CRISPR Systems ed. Y. Qi (New York, NY: Humana Press), 327-335. doi: 10.1007/978-1-4939-8991-1_24

Maccaferri, M., Harris, N. S., Twardziok, S. O., Pasam, R. K., Gundlach, H., Spannagl, M., et al. (2019). Durum wheat genome highlights past domestication signatures and future improvement targets. Nat. Genet. 51, 885-895. doi: 10.1038/s41588-019-0381-3

Mansueto, P., Soresi, M., Iacobucci, R., La Blasca, F., Romano, G., D’Alcamo, A., et al. (2019). Non-celiac wheat sensitivity: a search for the pathogenesis of a self-reported condition. Ital. J. Med. 13, 15-23. doi: 10.4081/itjm.2019.1070

Mehravar, M., Shirazi, A., Nazari, M., and Banan, M. (2019). Mosaicism in CRISPR/Cas9-mediated genome editing. Dev. Biol. 445, 156-162. doi: 10.1016/j.ydbio.2018.10.008

Pastorello, E. A., Farioli, L., Conti, A., Pravettoni, V., Bonomi, S., Iametti, S., et al. (2007). Wheat IgE-mediated food allergy in European patients: $\alpha$-amylase inhibitors, lipid transfer proteins and low-molecular-weight glutenins. Int. Arch. Allergy Immunol. 144, 10-22. doi: 10.1159/000102609

Phizicky, E. M., and Hopper, A. K. (2010). tRNA biology charges to the front. Genes Dev. 24, 1832-1860. doi: 10.1101/gad.1956510

Qi, W., Zhu, T., Tian, Z., Li, C., Zhang, W., and Song, R. (2016). High-efficiency CRISPR/Cas9 multiplex gene editing using the glycine 
tRNA-processing system-based strategy in maize. BMC Biotechnol. 16:58. doi: 10.1186/s12896-016-0289-2

Qi, X., Dong, L., Liu, C., Mao, L., Liu, F., Zhang, X., et al. (2018). Systematic identification of endogenous RNA polymerase III promoters for efficient RNA guide-based genome editing technologies in maize. J. Crop Prod. 6, 314-320. doi: 10.1016/j.cj.2018.02.005

Reig-Otero, Y., Manes, J., and Manyes, L. (2018). Amylase-trypsin inhibitors in wheat and other cereals as potential activators of the effects of nonceliac gluten sensitivity. J. Med. Food 21, 207-214. doi: 10.1089/jmf.2017.0018

Sánchez-León, S., Gil-Humanes, J., Ozuna, C. V., Giménez, M. J., Sousa, C., Voytas, D. F., et al. (2018). Low-gluten, nontransgenic wheat engineered with CRISPR/Cas9. Plant Biotechnol. J. 16, 902-910. doi: 10.1111/pbi.12837

Scherf, K. A. (2019). Immunoreactive cereal proteins in wheat allergy, non-celiac gluten/wheat sensitivity (NCGS) and celiac disease. Curr. Opin. Food Sci. 25, 35-41. doi: 10.1016/j.cofs.2019.02.003

Schiffer, S., Rösch, S., and Marchfelder, A. (2002). Assigning a function to a conserved group of proteins: the tRNA $3^{\prime}$-processing enzymes. Embo. J. 21, 2769-2777. doi: 10.1093/emboj/21.11.2769

Schuppan, D., Pickert, G., Ashfaq-Khan, M., and Zevallos, V. (2015). Non-celiac wheat sensitivity: differential diagnosis, triggers and implications. Best. Pract. Res. Clin. Gastroenterol. 29, 469-476. doi: 10.1016/j.bpg.2015.04.002

Shan, Q., Wang, Y., Li, J., and Gao, C. (2014). Genome editing in rice and wheat using the CRISPR/Cas system. Nat. Protoc. 9:2395. doi: 10.1038/nprot.2014.157

Shewry, P. R. (2009). Wheat. J. Exp. Bot. 60, 1537-1553. doi: 10.1093/jxb/erp058

Shewry, P. R. (2019). What is gluten-why is it special? Front. Nutr. 6:101. doi: 10.3389/fnut.2019.00101

Sparks, C. A., and Jones, H. D. (2014). "Genetic transformation of wheat via particle bombardment", in Cereal Genomics: Methods and Protocols. Methods in Molecular Biology, eds R. J. Henry and A. Furtado (New York, NY: Humana Press), 201-218. doi: 10.1007/978-1-62703-715-0_17

Svitashev, S., Young, J. K., Schwartz, C., Gao, H., Falco, S. C., and Cigan, A. M. (2015). Targeted mutagenesis, precise gene editing, and site-specific gene insertion in maize using cas9 and guide RNA. Plant Physiol. 169, 931-945. doi: 10.1104/pp.15.00793

Tan, Y. Y., Yu, X. M., Shu, Q. Y., Zhang, H. L., Wang, S. G., Yuan, F. J., et al. (2016). Development of an HRM-based, safe and high-throughput genotyping system for two low phytic acid mutations in soybean. Mol. Breed. 36:101. doi: 10.1007/s11032-016-0529-0

Tang, X., Zhong, Z., Ren, Q., Liu, B., and Zhang, Y. (2019).” A Single transcript CRISPR-cas9 system for multiplex genome editing in plants", in Plant Genome Editing with CRISPR Systems, ed. Y. Qi (Humana Press, New York, NY), 75-82. doi: 10.1007/978-1-4939-8991-1_6

Tatham, A. S., and Shewry, P. R. (2008). Allergens to wheat and related cereals. Clin. Exp. Allergy 38, 1712-1726. doi: 10.1111/j.1365-2222.2008. 03101.x

Tundo, S., Lupi, R., Lafond, M., Giardina, T., Larré, C., Denery-Papini, S., et al. (2018). Wheat ATI CM3, CM16 and 0.28 allergens produced in pichia pastoris display a different eliciting potential in food allergy to wheat. Plants 7:101. doi: 10.3390/plants7040101
Wang, J. R., Wei, Y. M., Long, X. Y., Yan, Z. H., Nevo, E., Baum, B. R., et al. (2008). Molecular evolution of dimeric $\alpha$-amylase inhibitor genes in wild emmer wheat and its ecological association. BMC Evol. Biol. 8:91. doi: 10.1186/1471-2148-8-91

Wang, W., Simmonds, J., Pan, Q., Davidson, D., He, F., Battal, A., et al. (2018). Gene editing and mutagenesis reveal inter-cultivar differences and additivity in the contribution of TaGW2 homoeologues to grain size and weight in wheat. Theoret. App. Gen. 131, 2463-2475. doi: 10.1007/s00122-018-3166-7

Weichel, M., Glaser, A. G., Ballmer-Weber, B. K., Schmid-Grendelmeier, P., and Crameri, R. (2006). Wheat and maize thioredoxins: a novel cross-reactive cereal allergen family related to baker's asthma. J. Allergy Clin. Immunol. 117, 676-681. doi: 10.1016/j.jaci.2005.11.040

Xie, K., Minkenberg, B., and Yang, Y. (2015). Boosting CRISPR/Cas9 multiplex editing capability with the endogenous tRNA-processing system. Proc. Natl. Acad. Sci. U.S.A. 112, 3570-3575. doi: 10.1073/pnas.1420294112

Zapatero, L., Martinez, M. I., Alonso, E., Salcedo, G., Sánchez-Monge, R., Barber, D., et al. (2003). Oral wheat flour anaphylaxis related to wheat $\alpha$-amylase inhibitor subunits CM3 and CM16: wheat $\alpha$-amylase inhibitor subunits related to food allergy. Allergy 58, 956-956. doi: 10.1034/j.1398-9995.2003.00158.x

Zevallos, V. F., Raker, V., Tenzer, S., Jimenez-Calvente, C., Ashfaq-Khan, M., Rüssel, N., et al. (2017). Nutritional wheat amylase-trypsin inhibitors promote intestinal inflammation via activation of myeloid cells. Gastroenterology 152, 1100-1113. doi: 10.1053/j.gastro.2016.12.006

Zhang, Y., Liang, Z., Zong, Y., Wang, Y., Liu, J., Chen, K., et al. (2016). Efficient and transgene-free genome editing in wheat through transient expression of CRISPR/Cas9 DNA or RNA. Nat. Commun. 7:12617. doi: 10.1038/ncomms12617

Zhang, Z., Hua, L., Gupta, A., Tricoli, D., Edwards, K. J., Yang, B., et al. (2019). Development of an Agrobacterium-delivered CRISPR/Cas9 system for wheat genome editing. Plant Biotechnol. J. 17, 1623-1635. doi: 10.1111/pbi. 13088

Zhu, C., Bortesi, L., Baysal, C., Twyman, R. M., Fischer, R., Capell, T., et al. (2017). Characteristics of genome editing mutations in cereal crops. Trends. Plant. Sci. 22, 38-52. doi: 10.1016/j.tplants.2016.08.009

Zoccatelli, G., Sega, M., Bolla, M., Cecconi, D., Vaccino, P., Rizzi, C., et al. (2012). Expression of $\alpha$-amylase inhibitors in diploid Triticum species. Food Chem. 135, 2643-2649. doi: 10.1016/j.foodchem.2012.06.123

Conflict of Interest: The authors declare that the research was conducted in the absence of any commercial or financial relationships that could be construed as a potential conflict of interest.

Copyright (c) 2020 Camerlengo, Frittelli, Sparks, Doherty, Martignago, Larré, Lupi, Sestili and Masci. This is an open-access article distributed under the terms of the Creative Commons Attribution License (CC BY). The use, distribution or reproduction in other forums is permitted, provided the original author(s) and the copyright owner(s) are credited and that the original publication in this journal is cited, in accordance with accepted academic practice. No use, distribution or reproduction is permitted which does not comply with these terms. 